\title{
Family Functioning and Not Family Structure Predicts Adolescents' Reasoning and Math Skills
}

\author{
Yi-Ching Lin $\left(^{1}{ }^{1} \cdot\right.$ Princess-Melissa Washington-Nortey ${ }^{2} \cdot$ Oliver W. Hill $^{3} \cdot$ Zewelanji N. Serpell $^{2}$
}

Published online: 22 May 2019

(c) The Author(s) 2019

\begin{abstract}
Objectives A large body of research exists on families and their impact on children's developmental outcomes. Fewer studies examine family processes within different family structures and their impact on adolescents. This study extends prior work by evaluating associations between family structure (two biological parents, single-parent-mother only, and blended families with a step parent), family functioning (communication, cohesion and flexibility) and adolescents' logic and reasoning skills and math performance.

Methods A convenience sample of 269 African American adolescents was recruited from a university-based summer enrichment program. The sample was mostly female (63\%), with a mean age of 16.34 years. Data were derived from the baseline assessment during which participants completed the Family Adaptability and Cohesion Evaluation Scales (FACES IV), a computer-administered test of cognitive skills, and a paper-based math performance test.

Results Families with different structures varied in their family functioning (Wilks' $\Lambda=0.942, \mathrm{~F}_{(6,496)}=2.486, p=0.022$, $\left.\eta^{2}=0.835\right)$. Families differed on the dimensions of cohesion $\left(\mathrm{F}_{(2,250)}=5.80, p=0.003, \eta^{2}=0.044\right)$, flexibility $\left(\mathrm{F}_{(2,250)}=\right.$ $\left.5.48, p=0.005, \eta^{2}=0.042\right)$ and communication $\left(\mathrm{F}_{(2,250)}=5.80, p=0.003, \eta^{2}=0.047\right)$. Different dimensions of family functioning significantly predicted both logic and reasoning skills $\left(\mathrm{F}_{(7,244)}=2.14, p=0.040, \mathrm{R}^{2}=0.06\right)$ and math outcomes $\left(\mathrm{F}_{(7,142)}=3.16, p=0.004, \mathrm{R}^{2}=0.14\right)$.

Conclusions Families with different household structures differ in their functioning, including in their levels of cohesion, flexibility and communication. Family functioning is more important than family structure in predicting African American adolescents' reasoning skills and math performance.
\end{abstract}

Recent census bureau reports suggest that African American youth are developing in a wide range of family structures, with only about $35 \%$ being raised in a two-parent household (U.S. Census Bureau 2017). Considering the pervasive belief that family structure matters, this low rate has been put forward as an alarming trend (Carlson 2006). However, not all African American children raised in single-parent households end up with poor outcomes and many thrive (Taylor et al. 2010). Despite this fact, many researchers continue to adopt a "parental absence" perspective which

Zewelanji N. Serpell

znserpell@vcu.edu

1 Chang Gung University of Science and Technology, Taoyuan, Taiwan

2 Virginia Commonwealth University, Richmond, VA, USA

3 Virginia State University, Petersburg, VA, USA advocates two-parent households as the more favorable option (Amato and Keith 1991; Breivik and Olweus 2006; Turner et al. 2014) with little attention to other contextual factors that may promote adolescent development in a variety of family structures. Perhaps the most obviouspositive family functioning-is likely to yield positive outcomes irrespective of a family's structure.

Families are configured in a variety of ways, including two-parent biological families where both parents are married and living together; divorced families in which children live with one or both biological parents who are no longer married to each other; single-parent families consisting of an individual parent (mother or father) who may never have been married or are currently divorced; or blended families consisting of previously divorced but now remarried parent couples (Carlson 2006; Tartari 2015). A large corpus of studies has examined the impact of family structure on children's outcomes. Generally, research in this area suggests that academic failure, risky behavior and poor long- 
term educational outcomes are associated with family structure, such that children in single-parent, divorced, or blended families fare less well compared to their peers in two biological-parent households (Carlson and Corcoran 2001; Jablonska and Lindberg 2007; McLanahan and Sandefur 1994; Tartari 2015; Turner et al. 2014). Some studies suggest a similar adverse impact of non-two biological parent households on behavioral outcomes for adolescents (Barrett and Turner 2006; Jeynes 2005; Mak et al. 2010; Stark et al. 2016; Turner et al. 2014). However, most studies suggest that family structure may not work in isolation but in combination with a host of other factors such as maternal employment, maternal mental health, parental education and even parenting styles to impact child outcomes (Amato 2001; Astone and McLanahan 1991; Carlson 2006; Carlson and Corcoran 2001; Friedel et al. 2010). This complexity is nicely illustrated in a study by Carlson (2006) that showed that children residing in blended families may bear the brunt of their parents' failed relationship, and difficult transitions into and out of new relationships. Evidence from a two-year longitudinal study which began immediately after parental divorce, also showed that mothers who remained single or entered low quality relationships were more likely to report a decrease in well-being compared to mothers who entered high-quality relationships (Langlais et al. 2016). Yet, compared to mothers who entered low-quality relationships, mothers who remained single recorded higher levels of well-being. Consequently, parents who remain single after an initial divorce or who were never married and chose to remain unmarried after the conception and birth of a child, may provide socialization contexts for their children that support positive development especially if these contexts are stable and have complementary support from others.

Within each of the aforementioned family structures, family functioning may also be vastly different and the impact of that functioning on children may vary for a number of reasons. One important consideration is the developmental status of children within these families. Cognitive advancements that take place in middle childhood and continue to develop during adolescence change how youth relate with others around them (Wentzel 1994). Due to the increased cognitive competencies and desire for autonomy in adolescence, parenting and aspects of family functioning may be perceived as having little to contribute to cognitive outcomes than is the case for earlier stages of life (Laursen and Collins 2009; Noller and Callan 2015; Wentzel 1994). However, the increased emotional sensitivity and substantial growth in executive functioning skills in adolescence (Steinberg 2005) make family dynamics especially important determinants of school-related outcomes during this developmental period. For example, Wentzel (1994) found that parent-adolescent hostility was negatively associated with adolescents' academic outcomes.
Family functioning has received some attention in the literature, but most researchers have not focused on cognitive or academic outcomes. Dimensions of family functioning which have been examined in previous studies include: family intactness, family communication, family cohesion, adaptability and problem solving (Crane et al. 2005). Family communication is about how family members engage in conversation with one another and the rules that guide these conversations. While some families have strict rules regarding the nature and protocols of family conversations, others are easygoing and permit all forms of communication. Family cohesion refers to the degree of connectedness experienced among family members. Extremely cohesive families or enmeshed families may inhibit the development of autonomy and an independent sense of self in their children (Michael-Tsabari and Lavee 2012; Olson et al. 1983). Adaptability refers to a family's ability to alter its current functioning in response to influential internal and external factors of change. Problem solving, although like adaptability, specifically refers to a family's ability to sustain peaceful co-existence while resolving problems or issues of conflict (Crane et al. 2005).

Studies examining the impact of family functioning on adolescents have tended to focus on wellbeing outcomes such as depression, disease management, delinquency and other behavioral outcomes (Crane et al. 2005; Gavin et al. 1999). For example, among a sample of Chinese adolescents living in Canada and the United States, lower family functioning was associated with higher rates depression and delinquency (Crane et al. 2005). In one of the few studies examining the impact of family functioning on adolescents' school-related outcomes, Annunziata et al. (2006) sampled 211 African American adolescents and found that for boys -when paired with high levels of parental monitoringfamily cohesion led to higher levels of school engagement. For girls, there was a significant additive effect of family cohesion and parental monitoring, and together they enhanced school engagement. In sum, most studies examining the impact of family structure and family functioning on student outcomes focus on younger children. Those that include adolescent samples, have focused more on the impact of family functioning on adolescents' well-being and less on cognitive outcomes.

The present study investigates three main research questions: (1) are there significant differences in cognitive and academic outcomes as a function of family structure; (2) do significant differences in family functioning exist in different family structures; and (3) does family functioning better predict adolescents' performance outcomes than family structure. It specifically explores the degree to which family structure (two biological-parents, two-blended family parents, and single-parent) and different dimensions of family functioning predict African American 
adolescents' reasoning skills and math performance. Three dimensions of family functioning - cohesion, flexibility, and communication-are assessed as conceptualized in the Olson et al. (2007) Circumplex model. Family cohesion is defined as family members' emotional bonding with one another. It is comprised of two subcategories: balanced family cohesion and unbalanced cohesion (e.g. family disengagement and family enmeshment). Family disengagement is characterized by low levels of balanced cohesion, i.e. lack of emotional closeness within the family and lack of relational closeness between the parent and child. Family enmeshment is indicated by the amounts of time spent together as a unit. It is also a reflection of parental monitoring of their children's behaviors, and the degree to which they offer assistance in solving the children's emotional difficulties. The family flexibility dimension refers to the amount of change in family leadership, role relationship, and relationship rules in a family unit, and includes a balanced flexibility score and unbalanced flexibility score. Family flexibility is measured on a continuum with unbalanced scores of chaos and rigidity representing extreme ends of the spectrum and as indicators of problems with organization and leadership in a family. Parents are either too lenient, which leads to a chaotic system, or too strict, which leads to a rigid system. Lastly, family communication is viewed as a facilitating dimension for helping a family to support cohesion and flexibility (Olson and Gorall 2006). In the Circumplex model, children with poor outcomes are more likely to come from unbalanced family systems (Olson and Gorall 2006).

\section{Method}

\section{Participants}

The study sample included 269 adolescents (90.7\% selfidentified as African American, 9.3\% as from other racial/ ethnic minority group backgrounds, and $1.1 \%$ as European American). The sample was mostly female (63\%) and ages ranged from 12.38 to 19.46 years, with a mean age of 16.34 years. All participants were recruited from a universitybased summer enrichment program in the southeastern region of the United States.

\section{Procedure}

At the beginning of the summer-enrichment program, and after completing informed consent procedures, all students with parental consent or who were over the age of 18 selfadministered on a computer the following: the background questionnaire, the FACES IV survey, and Gibson's
Cognitive Skills Test. Participants completed a paper and pencil test of math performance.

\section{Measures}

\section{Background questionnaire}

A brief questionnaire that included six questions regarding participants' racial and ethnic background, age, gender, educational level, and the family structure (two-biological parents, a single parent, blended family that includes a step parent) within their household. Gender and age were used as control variables.

Family functioning was assessed using the FACES IV (Olson et al. 2007). Based on the Circumplex Model of Marital and Family Systems, this measure is a well accepted self-report instrument for evaluating family function in clinical settings (Kouneski 2002; Olson and Gorall 2006). In this study combinations of two balanced and four unbalanced scales derived from the extreme ends of each balanced scale, were used to characterize family functioning as healthy or problematic. Specifically, cohesion and flexibility represent the two balanced scales while disengaged, enmeshed (extreme ends of the cohesion scale) and, rigid and chaotic (extreme ends of the flexibility scale) represent the four unbalanced scales. Family functioning is described as healthy or problematic based on combinations of these balanced and unbalanced scales in each unit (Olson and Gorall 2006). Three family dimensions are computed based on the balanced and unbalanced scales: cohesion, flexibility and communication.

Computations of family cohesion and flexibility scores are adjusted up or down based on whether the difference between its two extreme scales is at the upper or lower end of the continuum. Therefore, higher levels of enmeshment compared to disengagement result in an upward adjustment of cohesion scores while a higher level of disengagement compared to enmeshment results in a downward adjustment of family cohesion scores. Similarly, higher levels of rigidity scores compared to chaotic scores results in a downward adjustment of flexibility scores while higher levels of chaotic scores compared to rigidity scores result in an upward adjustment of flexibility scores.

Scores of enmeshment and disengagement (the extreme scores of cohesion) were adjusted such that higher levels of enmeshment compared to disengagement scores result in higher cohesion scores while higher levels of disengagement compared to enmeshment result in lower cohesion scores for the family. Similarly, computations of flexibility scores incorporate scores of rigidity and chaos (the extreme scores of flexibility) such that higher scores on rigidity compared to chaotic scores negatively impact flexibility 
Table 1 Distribution patterns of family functioning by family structure

\begin{tabular}{lllllll}
\hline & $\begin{array}{l}\text { Cohesion } \\
\text { healthy }\end{array}$ & $\begin{array}{l}\text { Cohesion } \\
\text { unhealthy }\end{array}$ & $\begin{array}{l}\text { Flexibility } \\
\text { healthy }\end{array}$ & $\begin{array}{l}\text { Flexibility } \\
\text { unhealthy }\end{array}$ & $\begin{array}{l}\text { Cohesion- } \\
\text { flexibility } \\
\text { healthy }\end{array}$ & $\begin{array}{l}\text { Cohesion- } \\
\text { flexibility } \\
\text { unhealthy }\end{array}$ \\
\hline Two parents & $79 \%$ & $14 \%$ & $84 \%$ & $9 \%$ & $82 \%$ & $12 \%$ \\
Single parent & $65 \%$ & $31 \%$ & $70 \%$ & $26 \%$ & $72 \%$ & $24 \%$ \\
Blended family & $58 \%$ & $38 \%$ & $63 \%$ & $31 \%$ & $58 \%$ & $38 \%$ \\
\hline
\end{tabular}

Table 2 Means, standard deviations, and ranges for all variables in the current study

\begin{tabular}{lrrrr}
\hline Variable & Mean & \multicolumn{1}{c}{ Std. } & \multicolumn{1}{c}{ Max. } & \multicolumn{1}{c}{ Min. } \\
\hline Cohesion dimension & 58.05 & 29.39 & 107.75 & -7.50 \\
Flexibility dimension & 58.70 & 21.72 & 98.00 & -4.75 \\
Communication dimension & 36.91 & 7.29 & 50.00 & 13.00 \\
Logic and reasoning & 9.96 & 0.21 & 9.55 & 10.38 \\
Math performance & 14.73 & 4.75 & 24.00 & 4.00 \\
\hline
\end{tabular}

scores, while higher scores on chaotic scores compared to rigidity scores positively impact flexibility scores.

The communication score is envisioned as a facilitating dimension that aids families in altering their levels of cohesion and flexibility. It is measured as the total score of 10 questions on a 5-point Likert scale. Specific formulae for computing cohesion, flexibility and communication are shown below:

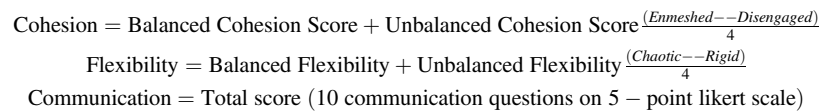

\section{Gibson cognitive skills test}

The logic and reasoning subtest-a set of matrix reasoning tasks - was used to assess students' reasoning ability and is similar to and correlated with performance on the Raven's Progressive Matrices (Raven 2003; Kiplinger 2008). This subtest is comprised of patterned images with a missing segment that participants were required to fill in. Participants were given six options from which to select the best solution. The logic and reasoning subtest of the Gibson test includes 20 test trials, and the score is the sum of correct trials; ranging from 0 to 20. Psychometric properties of this test indicate it is a reliable and valid test of cognitive skills in US populations aged 5 to 85 (Moore and Miller 2018).

\section{Mathematics performance}

The algebra subtests of two state-mandated mathematics assessments: the Virginia Standards of Learning Test practice items released in 2007 (SOL; Virginia Department of Education, http://www.doe.virginia.gov/testing/sol/sta ndardsdocs/index.shtml) and items released in 2008 from
Table 3 Means and standard deviations for family cohesion, flexibility, and communication dimensions by family structures

\begin{tabular}{|c|c|c|c|c|c|c|}
\hline \multirow[b]{2}{*}{ Variable } & \multicolumn{2}{|c|}{$\begin{array}{l}\text { Two } \\
\text { parents }\end{array}$} & \multicolumn{2}{|l|}{$\begin{array}{l}\text { Single } \\
\text { parent }\end{array}$} & \multicolumn{2}{|c|}{$\begin{array}{l}\text { Blended } \\
\text { family }\end{array}$} \\
\hline & Mean & Std. & Mean & Std. & Mean & Std. \\
\hline Cohesion dimension & 64.04 & 2.60 & 54.00 & 2.90 & 46.61 & 5.32 \\
\hline Flexibility dimension & 63.10 & 1.93 & 55.49 & 2.15 & 51.02 & 3.94 \\
\hline Communication dimension & 38.49 & 0.64 & 35.65 & 0.71 & 34.56 & 1.30 \\
\hline
\end{tabular}

the California Standards Tests (http://www.cde.ca.gov/ta/tg/ sr/documents/cstrtqalgebra.pdf).

\section{Data Analyses}

Descriptive analyses were conducted to assess sample characteristics on each of the study variables (see Tables 1-3). Preliminary data screening was conducted using the Box M test and Levene's test. Results did not indicate any violations of the assumption of multivariate normality, the assumption of linearity of associations, nor the assumption of homogeneity of variance matrices across outcome variables. In all subsequent analyses age and gender were entered as covariates. A one-way MANCOVA was used to answer the first research question-whether students would differ in cognitive outcomes as a function of their family structure. A second oneway MANCOVA examined whether the three family structures differed in their functioning (family cohesion, flexibility, and communication). Lastly, a hierarchical multiple regression analysis was used to test whether family structure and family functioning predict students' cognitive and math performance after controlling for age and gender.

\section{Results}

Descriptive analyses indicated that $49.4 \%$ of the sample reported living with two biological parents, $38.7 \%$ were living in single-parent families, and $11.9 \%$ were living in two-parent families in which one parent was a step-parent. A cohesion ratio, flexibility ratio, and cohesion-flexibility ratio were computed from two balanced and four unbalanced family subcategories. Based on definitions of healthy family functioning from the Circumplex model, preliminary 
analyses indicate that $75.8 \%$ of the sample was living in a family categorized based on the cohesion ratio as cohesivehealthy, $80.6 \%$ based on the flexibility ratio were categorized as flexible-healthy, and $79.2 \%$ were from healthy families that were both cohesive and flexible. Table 1 provides descriptive information on family functioning by family structure.

Results of the one-way MANCOVA controlling for gender and age, revealed no significant differences in cognitive or math outcomes based on family structure (two-parent biological, two-parent step or single parent $)\left(\mathrm{F}_{(4,520)}=0.131\right.$, $p>0.05)$, A second one-way MANCOVA was run to examine whether family structures differed in their functioning, and revealed significant differences among the three family structures. The overall effect of family structures on the set of family dimensions investigated was significant (Wilks' $\Lambda=0.942, \mathrm{~F}_{(6,496)}=2.486, p=0.022, \eta^{2}=0.835$ ). There were significant differences between participants in the different family structures on cohesion $\left(\mathrm{F}_{(2,250)}=5.80, p=\right.$ $\left.0.003, \eta^{2}=0.044\right)$, flexibility $\left(\mathrm{F}_{(2,250)}=5.48, p=0.005\right.$, $\left.\eta^{2}=0.042\right)$ and communication $\left(\mathrm{F}_{(2,250)}=5.80, p=0.003\right.$, $\left.\eta^{2}=0.047\right)$. Means and standard deviations are displayed in Table 3.

A hierarchical multiple regression analysis was used to test whether family structure and family functioning (family cohesion, flexibility, and communication) predict students' cognitive and math performance after controlling for age and gender. The results showed the model significantly predicted students' cognitive $\left(\mathrm{F}_{(7,244)}=2.14, p=0.040\right.$, $\left.\mathrm{R}^{2}=0.06\right)$ and math outcomes $\left(\mathrm{F}_{(7,142)}=3.16, p=0.004\right.$, $\mathrm{R}^{2}=0.14$ ) (see Table 4). Specifically, cohesion $(\beta=0.234$, $p<0.05)$ and flexibility $(\beta=-0.207, p<0.05)$ were significant predictors of students' logic and reasoning. The full model accounted for $5.8 \%$ of the variance in logicreasoning. Students' math performance was only significantly predicted by the cohesion $(\beta=0.246, p=0.042)$.
The full model accounted for about $13.5 \%$ of the variance in math performance.

\section{Discussion}

Previous research highlights the importance of family structure on varied domains of children's development, including school achievement, social well-being and psychological adjustment. However, the type of functioning evident in a family may equally influence youth outcomes. This study investigated the influence of both family structure and functioning on cognitive outcomes in adolescence: logic and reasoning and math outcomes. Findings attest to differences in family functioning across family structures, and that functioning significantly predicts cognitive outcomes in African American adolescent samples. It was noteworthy that family cohesion positively predicted math outcomes and logic and reasoning skills, whereas family flexibility was negatively associated with logic and reasoning.

These findings parallel recent assertions of the importance of family cohesion in development. Costigan et al. (2017), state in a recent handbook on positive development of minority children and youth, that family cohesion is an important variable associated with higher-order problem solving skills among middle school-aged populations. Other studies indicate that family cohesion together with parental support and parental expectations significantly predicts academic outcomes in White college students but in another study no such associations were witnessed among African American adolescent students (Walker and Satterwhite 2002). Based on the findings of this study, the authors suggested that the influence of family variables on college student success may be minimal and specific to some ethnic groups only (Walker and Satterwhite 2002). Further research is therefore needed to establish how
Table 4 Family structures and family functioning predict students' performance outcomes

\begin{tabular}{|c|c|c|c|c|c|}
\hline \multirow[t]{2}{*}{$\overline{\text { Variable }}$} & & \multicolumn{2}{|l|}{ Logic and reasoning } & \multicolumn{2}{|l|}{ Math outcomes } \\
\hline & & $\beta$ & $R_{\text {change }}^{2}$ & $\beta$ & $R_{\text {change }}^{2}$ \\
\hline \multirow[t]{2}{*}{ Step 1.} & Age & 0.064 & 0.019 & 0.270 & \\
\hline & Sex (control) & -0.127 & & -0.168 & $0.091 *$ \\
\hline \multirow[t]{2}{*}{ Step 2.} & Family_single-parent & -0.020 & 0.001 & -0.040 & \\
\hline & Family_blended family & 0.016 & & 0.055 & $0.005^{*}$ \\
\hline \multirow[t]{7}{*}{ Step 3.} & Cohesion dimension & $0.234^{*}$ & $0.038^{*}$ & $0.246^{*}$ & $0.039 *$ \\
\hline & Flexibility dimension & $-0.207^{*}$ & & -0.108 & \\
\hline & Communication dimension & -0.110 & & 0.218 & \\
\hline & & Intercept $=11.092 * *$ & & Intercept $=10.002 *$ & \\
\hline & & $R=0.241$ & & $R=0.367$ & \\
\hline & & $R^{2}=0.058$ & & $R^{2}=0.135$ & \\
\hline & & $R_{a d j}^{2}=0.031$ & & $R_{a d j}^{2}=0.092$ & \\
\hline
\end{tabular}

The control variables were age and gender ${ }^{*} p<0.05, * * p<0.001$ 
family processes influence adolescent outcomes in African American samples.

The findings related to the influence of family flexibility on adolescent cognitive outcomes support previous research which suggests that adolescents demonstrate better cognitive functioning in environments with high levels of organization, limit setting and parental support (Schroeder and Kelley 2010), thus low flexibility. This may suggest that low levels of flexibility may be beneficial for adolescent success since these environments lend themselves to higher levels of structure and monitoring. We find that higher levels of flexibility (i.e. low monitoring) were associated with lower levels of logic and reasoning. There are at least two possible explanations for why this may be the case. The first pertains to the period of adolescence itself, while the second may be reflective of the consequences of extreme behaviors or practices. Firstly, during the period of adolescence which has been associated with volatile emotional states (Steinberg 2005), adolescents may require additional attention, limit setting and organization within a household to facilitate some cognitive capacities such as logic and reasoning. The effects of excessive household flexibility coupled with an increased desire for behavioral autonomy and freedom may actually lead to more negative outcomes. Similarly, just as studies on parental monitoring suggest that excessive parental monitoring may actually result in poorer child outcomes and increased incidences of risky behavior, excessive family flexibility may also result in equally negative outcomes for adolescents. These results highlight the importance of developmental considerations when studying the impact of parenting on youth outcomes. Additionally, a few other studies hint that family communication may be associated with cognitive outcomes in adolescence (Schroeder and Kelley 2010). Specifically, parent-child communication-an index of parental involvement - has been found to be positively associated with adolescent outcomes in high school and college settings (Patrikakou 2004). On this basis, parents have been encouraged to maintain open lines of communication with their adolescents (Patrikakou 2004). Findings on this front in the current study were non-significant, indicating no influence of parent-child communication on adolescents' cognitive outcomes. Our results may be attributable to our measurement approach or reflect an interesting dynamic present in parent-child relationships during the period of adolescence. Perhaps excessive parent-child communication, like excessive flexibility may negatively influence adolescent cognitive outcomes. Again, additional research is needed to bring more clarity to these findings.

Although there were no significant differences in cognitive outcomes based on family structure, two-parent biological, single-parent, and two parent step-parent/blended families differed in their family functioning. More specifically, findings showed that two-parent biological families differed significantly from single-parent and twoparent step-parent/blended families on cohesion, flexibility and communication, and on each dimension children from two-parent biological families reported better family functioning. This may be due to higher levels of stability, fewer conflicts or disruptions, economic reasons or a host of other reasons. Pairwise comparisons did not yield significant differences in family function between single-parent families and two-parent step-parent/blended families on any of the dimensions of family functioning assessed: cohesion, flexibility and communication. However, an examination of mean levels revealed that two-parent stepparent/blended families possessed the lowest scores. As such, results indicate that family functioning within twoparent step parent/blended families are not better than those observed in single-parent households. This finding may be related to the fact that we assess family functioning from the perspective of the adolescent participant. In adolescence, two-parent step-parent/blended families may present a number of unique challenges for adolescents as they frequently require periods of adjustment or readjustment (Kobak et al. 2017; Parra et al. 2015). For instance, blending children from previous marriages may require a considerable level of adjustment for all parties involved. Additionally, relationships with former spouses and/or birth parents, as well as relationships with new spouses or partners who may have different temperaments, may contribute significantly to the process of adjustment.

Our findings, similar to those of prior studies, suggest that the nature of the relationship within a family structure may supercede the structure itself (Lansford et al. 2001). It is also important to note that not all studies find that family functioning varies by family structure. For example, Hornberger et al. (2010) showed that identical levels of family functioning were found in single-parent and dualparent families. Our findings suggest that single parenting status may not necessarily impede adolescents' functioning more or less than a two-parent family context in which one of the parents is a step-parent.

\section{Limitations and Future Directions}

This study is one of very few studies that examine how family functioning contributes to cognitive outcomes (logic and reasoning) and math performance during the period of adolescence. It includes a novel examination of the Circumplex model and establishes that family functioning is a better predictor than family structure of adolescents' cognitive and academic outcomes. However, this study sampled a predominantly African American adolescent sample, a factor which restricts generalizability of findings to other adolescent populations within the United States, and globally. Secondly, 
adolescents in our sample were recruited from a summerbridge program and were therefore more likely to come from intact families of relatively high and/or stable socio-economic standing. This may have significantly influenced the nature of our results and further limits the generalizability of our findings. Finally, the fact that family functioning was reported by adolescents may have reduced the objectivity of our data especially since we know this is a relationally-challenging time for adolescents and any instability or perception thereof may impact these perceptions. Future studies should examine more diverse socio-economic groups to increase ecological validity and generalizability of these findings. In addition, they should examine responses from multiple respondents to ascertain whether results will vary from those we have reported in this study.

Acknowledgements This research was supported by funding from the National Science Foundation HRD-1137535 and DRL-1621416.

Author Contributions Y.C.L. developed the research questions, analyzed the data, wrote the results section and the first draft of the manuscript. P.M.W.N. provided feedback on the manuscript and contributed to writing the introduction and discussion sections of the manuscript. O.W.H. designed and executed the study and provided feedback on the manuscript. Z.N.S. designed and executed the study, helped conceptualize the framework for the paper, wrote the methods section, collaborated in analyzing the data and in writing and editing the final manuscript.

\section{Compliance with Ethical Standards}

Conflict of Interest The authors declare that they have no conflict of interest.

Ethics Statement All procedures performed in this study were in accordance with the ethical standards of the Institutional Review Board (IRB) at Virginia State University as well as with the 1964 Helsinki declaration and its later amendments or comparable ethical standards.

Informed Consent Informed parental consent, and informed adolescent assent was obtained from all participants in the study.

Publisher's note: Springer Nature remains neutral with regard to jurisdictional claims in published maps and institutional affiliations.

Open Access This article is distributed under the terms of the Creative Commons Attribution 4.0 International License (http://crea tivecommons.org/licenses/by/4.0/), which permits unrestricted use, distribution, and reproduction in any medium, provided you give appropriate credit to the original author(s) and the source, provide a link to the Creative Commons license, and indicate if changes were made.

\section{References}

Amato, P. R. (2001). Children of divorce in the 1990s: an update of the Amato and Keith (1991) meta-analysis. Journal of Family
Psychology, 15, 355-370. https://doi.org/10.1037/0893-3200.15. 3.355.

Amato, P. R., \& Keith, B. (1991). Parental divorce and the well-being of children: a meta-analysis. Psychological Bulletin, 110, 26-46. https://doi.org/10.1037/0033-2909.110.1.26.

Annunziata, D., Hogue, A., Faw, L., \& Liddle, H. A. (2006). Family functioning and school success in at-risk, inner-city adolescents. Journal of Youth and Adolescence, 35, 100-108. https://doi.org/ 10.1007/s10964-005-9016-3.

Astone, N. M., \& McLanahan, S. S. (1991). Family structure, parental practices and high school completion. American Sociological Review, 56, 309-320. https://doi.org/10.2307/2096106.

Barrett, A. E., \& Turner, R. J. (2006). Family structure and substance use problems in adolescence and early adulthood: examining explanations for the relationship. Addiction, 101, 109-120. https://doi.org/10.1111/j.1360-0443.2005.01296.x.

Breivik, K., \& Olweus, D. (2006). Adolescent's adjustment in four post-divorce family structures: single mother, stepfather, joint physical custody and single father families. Journal of Divorce \& Remarriage, 44, 99-124. https://doi.org/10.1300/J087v44n03_ 07.

Carlson, M. J. (2006). Family structure, father involvement, and adolescent behavioral outcomes. Journal of Marriage and Family, 68, 137-154. https://doi.org/10.1111/j.1741-3737.2006. 00239.x.

Carlson, M. J., \& Corcoran, M. E. (2001). Family structure and children's behavioral and cognitive outcomes. Journal of Marriage and Family, 63, 779-792. https://doi.org/10.1111/j.1741-3737. 2001.00779.x.

Costigan, C., Taknint, J., \& Miao, S. (2017). Parenting and families in the United States and Canada. In N. J. Cabrera \& B. Leyendecker (Eds), handbook on positive development of minority children and youth (pp. 157-173). New York, NY: Springer Publishing. https://doi.org/10.1007/978-3-319-43645-6_10.

Crane, D. R., Ngai, S. W., Larson, J. H., \& Hafen, M. (2005). The influence of family functioning and parent-adolescent acculturation on North American Chinese adolescent outcomes. Family Relations, 54, 400-410. https://doi.org/10.1111/j.1741-3729. 2005.00326.x.

Friedel, J. M., Cortina, K. S., Turner, J. C., \& Midgley, C. (2010). Changes in efficacy beliefs in mathematics across the transition to middle school: examining the effects of perceived teacher and parent goal emphases. Journal of Educational Psychology, 102, 102-114. https://doi.org/10.1037/a0017590.

Gavin, L. A., Wamboldt, M. Z., Sorokin, N., Levy, S. Y., \& Wamboldt, F. S. (1999). Treatment alliance and its association with family functioning, adherence, and medical outcome in adolescents with severe, chronic asthma. Journal of Pediatric Psychology, 24, 355-365. https://doi.org/10.1093/jpepsy/24.4.355.

Hornberger, L. B., Zabriskie, R. B., \& Freeman, P. (2010). Contributions of family leisure to family functioning among singleparent families. Leisure Sciences, 32, 143-161. https://doi.org/10. 1080/01490400903547153.

Jablonska, B., \& Lindberg, L. (2007). Risk behaviours, victimisation and mental distress among adolescents in different family structures. Social Psychiatry and Psychiatric Epidemiology, 42, 656-663. https://doi.org/10.1007/s00127-007-0210-3.

Jeynes, W. H. (2005). Effects of parental involvement and family structure on the academic achievement of adolescents. Marriage \& Family Review, 37, 99-116. https://doi.org/10.1300/ J002v37n03_06.

Kiplinger, V. (2008). Online Gibson cognitive skills test: phase 1 report-item analysis, test reliability, \& effects of early termination rule. Lafayette, $\mathrm{CO}$ : Windwalker Consulting.

Kobak, R., Abbott, C., Zisk, A., \& Bounoua, N. (2017). Adapting to the changing needs of adolescents: parenting practices and 
challenges to sensitive attunement. Current Opinion in Psychology, 15, 137-142. https://doi.org/10.1016/j.copsyc.2017.02.018.

Kouneski, E. F. (2002). Five types of marriage based on ENRICH: linking intrapersonal and interpersonal characteristics. Twin Cities: University of Minnesota. Unpublished doctoral dissertation. https:// search.proquest.com/docview $/ 276382684$ ?pq-origsite $=$ primo.

Lansford, J. E., Ceballo, R., Abbey, A., \& Stewart, A. J. (2001). Does family structure matter? A comparison of adoptive, two-parent biological, single-mother, stepfather, and stepmother households. Journal of Marriage and Family, 63, 840-851. https://doi.org/10. 1111/j.1741-3737.2001.00840.x.

Langlais, M. R., Anderson, E. R., \& Greene, S. M. (2016). Consequences of dating for post-divorce maternal well-being. Journal of Marriage and Family, 78, 1032-1046. https://doi.org/10.1111/jomf.12319.

Laursen, B., \& Collins, W. A. (2009). Parent-child relationships during adolescence. 3-42. New York, NY: Wiley. https://doi.org/ 10.1002/9780470479193.adlpsy002002.

Mak, K. K., Ho, S. Y., Thomas, G. N., Schooling, C. M., McGhee, S. M., \& Lam, T. H. (2010). Family structure, parent-child conversation time and substance use among Chinese adolescents. BMC Public Health, 10, 503. https://doi.org/10.1186/1471-2458-10-503.

McLanahan, S., \& Sandefur, G. (1994). Growing Up with a Single Parent. What Hurts, What Helps. Cambridge, MA: Harvard University Press.

Michael-Tsabari, N., \& Lavee, Y. (2012). Too close and too rigid: applying the circumplex model of family systems to first-generation family firms. Journal of Marital and Family Therapy, 38, 105-116. http://web.a.ebscohost.com/ehost/pdfviewer/pdfviewer?vid=1\&sid $=$ ff938948-2308-41a5-a544-7358f2c5edbc\%40sessionmgr4008.

Moore, A. L., \& Miller, T. M. (2018). Reliability and validity of the revised Gibson Test of Cognitive Skills, a computer-based test battery for assessing cognition across the lifespan. Psychology Research and Behavior Management, 11, 25-35. https://doi.org/ 10.2147/PRBM.S152781.

Noller, P., \& Callan, V. (2015). The adolescent in the family (1st ed.).1st edn London, UK: Routledge. https://doi.org/10.4324/ 9781315667836.

Olson, D. H., \& Gorall, D. M. (2006). Faces IV and the circumplex model. Minneapolis, MN: Life Innovations. http://citeseerx.ist.psu. edu/viewdoc/download?doi=10.1.1.567.7299\&rep=rep1\&type $=$ pdf.

Olson, D. H., Gorall, D. M. \& Tiesel, J. W. (2007). FACES IV \& the circumplex Model: validation study. Recuperado el 01/04/09 en www.facesiv.com Life Innovations.

Olson, D. H., Russell, C. S., \& Sprenkle, D. H. (1983). Circumplex model of marital and family systems: Vl. Theoretical update. Family Process, 22, 69-83. https://doi.org/10.1111/j.1545-5300. 1983.00069.x.

Parra, A., Oliva, A., \& Reina, M. D. C. (2015). Family relationships from adolescence to emerging adulthood: a longitudinal study. Journal of Family Issues, 36, 2002-2020. https://doi.org/10. 1177/0192513X13507570.
Patrikakou, E. (2004). Adolescence: are parents relevant to students' high school achievement and postsecondary attainment. Cambridge, MA: Harvard Family Research Project. https://www.resea rchgate.net/profile/Eva_Patrikakou/publication/317099531_ Adolescence_Are_Parents_Relevant_to_Students'_High_ School_Achievement_and_Post-Secondary_Attainment/links/ 59261b6a0f7e9b99799041f5/Adolescence-Are-Parents-Relevantto-Students-High-School-Achievement-and-Post-Secondary-Atta inment.pdf.

Raven, J. (2003). Raven progressive matrices. In R. S. McCallum (Ed.), Handbook of nonverbal assessment. (pp. 223-237). US: Springer. https://doi.org/10.1007/978-1-4615-0153-4_11.

Schroeder, V. M., \& Kelley, M. L. (2010). Family environment and parent-child relationships as related to executive functioning in children. Early Child Development and Care, 180, 1285-1298. https://doi.org/10.1080/03004430902981512.

Stark, L., Tan, T. M., Muldoon, K. A., King, D., Lamin, D. F., Lilley, S., \& Wessells, M. G. (2016). Family structure and sexual and reproductive health outcomes among adolescents in rural Sierra Leone. Global Public Health, 11, 309-321. https://doi.org/10. 1080/17441692.2015.1031155.

Steinberg, L. (2005). Cognitive and affective development in adolescence. Trends in Cognitive Sciences, 9, 69-74. https://doi.org/10. 1016/j.tics.2004.12.005.

Tartari, M. (2015). Divorce and the cognitive achievement of children. International Economic Review, 56, 597-645. https://doi.org/10. 1111/iere.12116.

Taylor, Z. E., Larsen-Rife, D., Conger, R. D., Widaman, K. F., \& Cutrona, C. E. (2010). Life stress, maternal optimism, and adolescent competence in single mother, African American families. Journal of Family Psychology, 24, 468-477. https://doi.org/10. 1037/a0019870.

Turner, R. A., Irwin, Jr, C. E., \& Millstein, S. G. (2014). Family structure, family processes, and experimenting with substances during adolescence. Risks and Problem Behaviors in Adolescence, 1, 229-247.

U.S. Census Bureau (2017). Families and living arrangements. Washington, D.C.: Government Printing Office. U.S. Census Bureau (2017). https://www.census.gov/hhes/families/data/fa milies.html.

Walker, K. L., \& Satterwhite, T. (2002). Academic performance among African American and Caucasian college students: is the family still important?. College Student Journal, 36, 113-128. http://web.a. ebscohost.com/ehost/detail/detail?vid $=2 \&$ sid $=$ c365dec0-b1b5-420 9-853a-25647f035ace\%40sessionmgr4010\&bdata $=\mathrm{JkF1dGhUeX}$ BlPWlwLHVybCxjb29raWUsdWlkJnNpdGU9ZWhvc3QtbGl2ZS ZzY29wZT1zaXRl\#AN $=6539435 \& d b=a 9 h$.

Wentzel, K. R. (1994). Family functioning and academic achievement in middle school. A social-emotional perspective. The Journal of Early Adolescence, 14, 268-291. https://doi.org/10.1177/ 027243169401400209. 